\title{
Bioethics in the undergraduate medical curriculum: a review from the Indian subcontinent
}

\author{
Pinaki Wani \\ Department of Physiology, K.J. Somaiya Medical College and Research Centre, Sion, Mumbai, \\ Maharashtra, India \\ Corresponding Author : Pinaki Wani \\ E-mail: wanipinaki@gmail.com
}

\begin{abstract}
In the past few decades, there has been a tremendous biotechnologies breakthrough in the field of medicine combined with disturbed doctor-patient relationship bringing in various bioethical issues and challenges. There is a need of a systematic and standard approach to deal with these ethical issues which is missing in the Indian Medical undergraduate curriculum. The Indian medical system is based on age old traditional paternalistic Doctor- patient relationship which is imposed on the students. However the understanding of rights of the patients along with the responsibilities and duties of health professionals to be able to understand, analyse and make appropriate ethical decisions is the need of the hour. This paper focuses on the requirement of introduction of bioethics curriculum in Indian scenario, challenges faced, the attitude of the undergraduate medical students towards ethics and the changes taking place in the current field of bioethics in Indian undergraduate medical education.
\end{abstract}

Key words: bioethics, curriculum, medical, Indian, undergraduate

\section{INTRODUCTION}

The prime objective of a medical curriculum is to produce clinically competent medical practitioners having a set code of behaviour towards the society [1]. In the past, this relationship between the doctor and patient was paternalistic [2]. However, there has been a tremendous change in the field of medical sciences and technologies in the recent few decades. These advancements have created new dilemmas eg. euthanasia, intensive care, pain management, medical genetics and biotechnologies, procreation causing previous ethical resolutions to become obsolete and ruining the patient- physician relationship thus increasing the gap between medicine and society at large. As mentioned by Dr S.K. Pandya in The National Medical Journal of India, that today "unfortunately the number of role models in the medical colleges is diminishing as unethical practices flourish and this adds to the frustration of students for they see a divergence between what is preached and what is practised" [3-5]. This has posed a requirement of introducing bio ethics in the undergraduate medical curriculum. The application of the Consumer Protection Act to the medical profession has stimulated medical professional to consider medical ethics in their annual deliberations. Reports of misconduct between doctorpatients, in research, and the Indian Council of Medical Research (ICMR) guidelines on clinical trials, have stimulated a keen interest in the study of bioethics in our country [3]. 


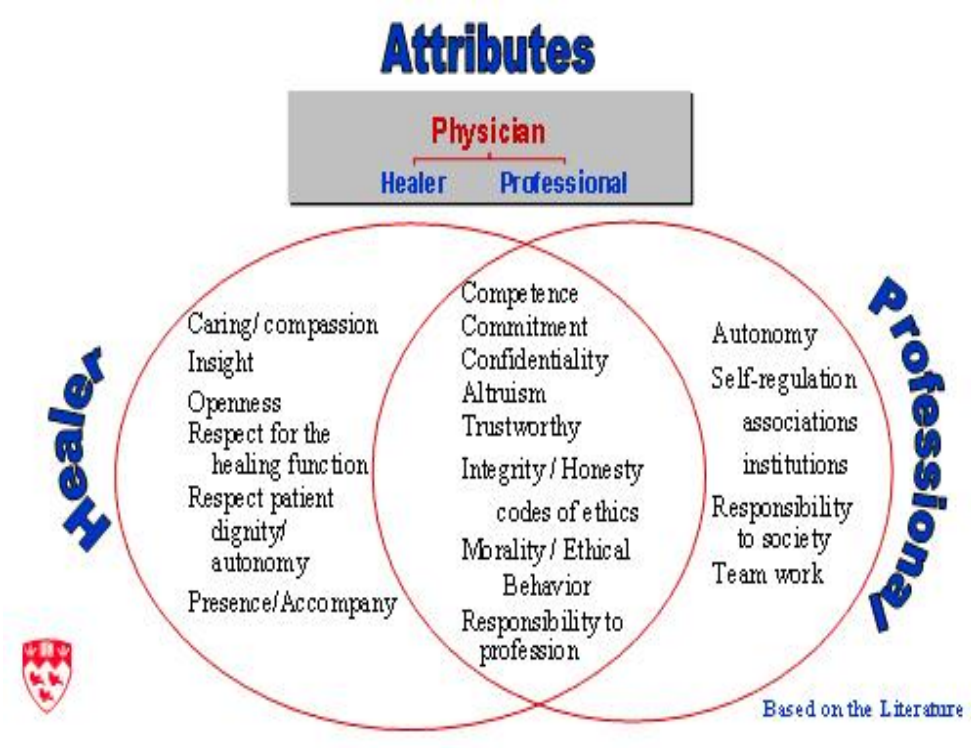

Figure 1 - Bioethics education: the core aims

So what is Bioethics? "Bioethics" word was coined by a biochemist, Van rensselaer potter, in 1970 is "a field of study concerned with the ethics and philosophical implications of certain biological and medical procedures, technologies, and treatments, as organ transplants, genetic engineering, and care of the terminally ill". Professor Dunstan gives a succint but good definition of medical ethics- "obligations of a moral nature which govern the practice of medicine" [6].

Across the world, Bioethics is now regarded as an integral part of contemporary medical education. Well defined strategies have been developed and are in place for undergraduate as well as postgraduate bioethics education [7]. The four basic, accepted, moral obligations or principals of bioethics in a doctor-patient relationship in all societies are, patient autonomy, nonmaleficence, beneficence and justice.

Autonomy: Health professionals should enquire about their patient's wishes to receive information and to make decisions - it is a professional obligation.

Non-maleficence: It obligates the doctors to abstain from causing harm to others and supports several moral rules, including :Do not kill, Do not cause pain or suffering, Do not incapacitate, Do not deprive others of the goods of life.

Beneficence: It means doctors must take positive steps to help people and not merely refrain from harm. Patient welfare embodies medicine's goal, justification and rationale - include public health, preventative medicine and biomedical research.

Justice: is the need to improve both utility (efficiency) and justice (fairness and equality). It is the judicious balance between these obligations that determines ethical decisions in a given clinical situation [8].

\section{CURRENT SCENARIO OF BIOETHICS TEACHING IN UNDERGRADUATE MEDICAL CURRICULUMS IN INDIA}

In the existing medical education, the Medical Council of India (MCI) curriculum does not have "Medical ethics" as a separate subject in any of its courses. In this curriculum of phase II, Forensic Medicine, the students learn about the principles of medical ethics, mainly the legal aspects in brief and it is taught in four to five hours. In the study done by Akoijam Brogen and others [9] to understand the knowledge and attitudes of medical students on medical ethics in a teaching hospital, they found the lack and inadequacy of the knowledge regarding codes of ethics and its curriculum during the undergraduate medical teaching. They also stressed on the need of inclusion of ethics in the medical curriculum through lectures, seminars, workshops or 
continuing medical education (CME). The article also highlighted the unawareness of the role played by the ethical committee in the medical institution. A similar study done by Biswajit Chatte [10] showed only $10.9 \%$ of the student's awareness of the existence of the institutional ethics committee and many of them did not know its specific functions. This highlights the need for the institutional ethics committee of teaching hospitals to publicise their work at regular intervals for the benefit of trainees. The institutional ethics committee should publish reports related to its involvement in different health-related activities within the institution, and these should be circulated among the students as well. The study also revealed that there is no proportionate increase in awareness of ethical issues along with an increase in the years of medical education; the mean score of second year students was better than that of their seniors. Similar findings were reported in other studies [11-12]. This suggests that the mode of teaching, predominantly didactic and text book-oriented does not increase students' awareness of this subject. Clinically-oriented approaches with interactive components through case studies and workshops may be more effective. A similar study done by Hariharan also showed $52 \%$ of senior medical staff and $20 \%$ of senior nursing staff at their institution knew little of the laws pertaining to their work [13]. Due to these lacunae, the students are expected to "observe the principles of medical ethics in the practice of his profession". However as undergraduate medical students, who are already coping with various challenges like adjusting with the new learning environment, inadequate communication skills, insufficient orientation towards procedures and practices, scholastic performance and economic stress, they are left with no time and inclination to spare a thought for the hardships of others [14]. When passing an exam and scoring is the main goal, the patient is bound to get relegated to being "just a case". This habits formed during these undergraduate years continue into residency and become the guiding principles of practice thereafter [15]. The situation does not appear to improve once medical education is completed, and it may even worsen as trainees progress through education, as shown by many studies .A three-year cohort study by Patenaude and others [12], found that students' understanding of ethics did not improve substantially with education. $72 \%$ of the students surveyed remained at the same stage of moral reasoning in their third year of study as in their first, as evidenced by mean scores of 3.46 in the first year and 3.48 in the third year. In fact, $13 \%$ moved down to the lower stage and only $15 \%$ moved to the higher stage.. The mean attitude score in relation to the intimate examination of patients to adhere to rules regarding informed consent and confidentiality also showed that second and third year students had higher mean scores than their seniors.

In addition to this, the following are some issues faced by undergraduate medical students -

1. Lack of bioethics curriculum: The time allotted for and the quality of the medical bioethics curriculum has a vast variation. Very few colleges have a department of bioethics with a faculty that is trained in bioethics and is dedicated to teaching medical students; and there are a handful of colleges that have engaged in the development and evaluation of an ethics curriculum.

2. Lack of original content: The colleges that do have a bioethics curriculum in place often hit a dead end when it comes to offering study material. Since very little effort is made to develop these programmes in bioethics education, these courses are often poorly developed and are meagre in content. They mostly contain case studies and modules sourced or adapted from western medical literature.

3. Lack of substance: Most institutions offering ethics programmes satisfy only the minimum requirement of education in bioethics. They mostly accredit agencies and don't have proper services to ensure ethical care to patients themselves. Students from the medical sector have been demanding for practical teaching of ethics, where in a role play by those experienced in the field gives them a firsthand experience of the field.

4. Lack of finances: This is a critical barrier to providing good quality bioethical education in India apart from the lack of educational curricula development. Most medical institutions do not have a separate budget to run an ethics department. Encouraging faculty members to share their knowledge and experiences, logging of medical cases and sharing them with students are some ways to encounter this problem; though having a 
full swing staff and developing a model of teaching ethics is the best way to ensure a balance between professional medicine and ethical medicine.

5. Lack of resource persons: There is an acute shortage of trained medical ethics faculty in the country. There is an urgent need to train staff if medical ethics is to be introduced as a subject.

6. Lack of assessment of students and evaluation of the programme: The student needs to be assessed 360 degree for their understanding of bioethics subject along with the required attendance in the same

This lack of structured curriculum in bioethics and awareness of basic ethical principles and obligations results in coercion, forced decision making, reduced confidentiality, respect for the person and informed consent which leads to malpractices and hampers the routine of the hospital [16].

\section{THE ROAD AHEAD}

Various international survey conducted on medical ethics curricula in Asia with 89 out of 100 medical colleges have shown integration of bioethics in the medical curriculum to bridge these gaps in ethical understanding of the medical students Indian Council of medical Research (ICMR) has been conducting sensitization workshops on Bioethics to the students as well as faculty throughout the country since 2004. Few medical colleges in India have integrated formal teaching of Bioethics in the curriculum which includes St. John's Medical College India (1998) teaching medical ethics as a regular part of its undergraduate curriculum. The Kasturba Medical College, Manipal, has a series of sessions dealing with ethical issues, and several other medical colleges similarly have six to eight sessions on the subject. The Christian Medical College, Vellore, uses case studies during internship to inculcate ethical thinking in future doctors. According to Hafferty, training in medical ethics should be started early and continued throughout all of the basic and clinical sciences years. Since India presents a unique case of socio-economic, ethnic, multilingual, religious and cultural diversity. The most important need would be to inculcate the philosophy of ethical practices into the minds of medical students [7].

\section{MEDICAL COUNCIL OF INDIA VISION 2015}

On March 29, 2011, the Medical Council of India released Vision 2015 document [18] which discusses various reforms in the undergraduate and postgraduate medical curriculum. The aim of this medical curriculum is to build an effective and competent "Indian Medical Graduate", which means that the student who joins the Medical College needs studying medical sciences effectively. To achieve this, an orientation program is needed to sensitize and inculcate in the student the basic principles of self- learning, effective written, verbal and non- verbal communication skills, medical ethics, managing self, including stress and time management, professionalism community health and human values. It stresses to restructure the existing curriculum to "integrate ethics, attitudes and professionalism into all phases of learning" to "enable the Indian Medical Graduate to function professionally and ethically". This can be inculcated through a Foundation Course which is being planned right at the beginning of the course. This two-month course include elements of ethics, professionalism and communication skills besides giving students and orientation to national health policies, health economics, computer skills and an overview of anatomy, physiology and biochemistry. It also outlines plans to introduce early clinical exposure at the primary care level focusing on communication, clinical skills and professionalism. This curriculum also allows flexible learning options in the form of electives for two months in the field of bioinformatics, tissue engineering, ethics, genetics, sports medicine, assisted reproductive technology, and ethics and medical education where the students are expected to do a project and enhance self-directed learning, critical thinking and research abilities .In addition to this, in the month of March 2015, there was memorandum of understanding signed between MCI-MUHS-UNESCO to introduce vertically integrated Bioethics curriculum for the Undergraduate Medical students. 
The objectives of this curriculum are to enable medical students to -

1. Be able to identify the ethical issues, which occur during medical practice; also, be able to anticipate any issue, which might arise. Apply ethical principles to those issues and arrive at decisions.

2. Be able to defend his decisions, by providing rational justifications.

3. Additionally, be able to fine tune his decisions, on the basis of moral beliefs, and traditional practices in the particular cultural milieu [19].

The general 'principals of this curriculum are uniformity of the curriculum which incorporates all the 17 modules of the Bioethics Core Curriculum UNESCO 2008 ver1 and all the 15 principles and the 28 articles enshrined in the Universal Declaration on Bioethics and Human Rights of UNESCO 2005. Integrated teaching-learning method shall be employed with Innovative methods and standardised text books for leaning. Evaluation of the course curriculum, shall be done by constant feedback from students. Evaluation of the students' performance shall be achieved (a) by traditional written tests and (b) by non formal evaluation [19].

\section{CONCLUSION}

To conclude, teaching medical ethics in curricula in our medical schools will produce better young doctors who will be good managers of health care resources, advocate for patients and may be leaders for organizational change. A need of a well-constructed curriculum in medical ethics for undergraduates and young doctors to provide an array of competencies in dealing with ethical dilemmas has lead to various measures taken upon by the stakeholders of medical education in India. This will definitely be fruitful in future of medical education and clinical practice in India.

\section{Acknowledgement}

Professor Russell D'Souza, Head Asia Pacific Bioethics Program UNESCO Chair in Bioethics for the constant support and guidance in the field of bioethics

\section{REFERENCES}

1. Accreditation Council for Graduate Medical Education (ACGME). Outcome Project. http:// acgme.org/Outcome/. Accessed on 23 July, 2009.

2. Medical Council of India. Salient features of regulations on graduate medical education, Gazette of India. 1997 May 17; part III, section 4.

3. Ravindran GD. Medical ethics education in India. Indian J Med Ethics 2008;5(1):18-9.

4. Pandya SK. Clinical ethics: a practical approach. Natl Med J India 2006;19(6):340.

5. Ravindran GD, Kalam T, Lewin S, Pais P. Teaching medical ethics in a medical college in India. Natl Med J India 1997;10(6):288-9.

6. Udwadia FE. Ethical problems in medical education. Iss Med Ethics 1997;5(2):37-9.

7. Hadimani CP. Proposal for Integration of Bioethics in Phase I Undergraduate Medical Curriculum in India. International Journal of User-Driven Healthcare 2013;3(4):13-9.

8. http://patient.info/doctor/medical-ethics

9. Brogen SA, Rajkumari B, Laishram J, Joy A. Knowledge and attitudes of doctors on medical ethics in a teaching hospital, Manipur. Indian J Med Ethics 2009;6(4):194-7.

10. Chatterjee B, Sarkar J. Awareness of medical ethics among undergraduates in a West Bengal medical college. Indian J Med Ethics 2012;9(2):93-9.

11. Roberts LW, Green Hammond KA, Geppert GM, Warner TD. The positive role of professionalism and ethics training in medical education: a comparison of medical student and resident perspectives. Acad Psychiatry 2004;28(3):170-82.

12. Patenaude J, Niyonsenga T, Fafard D. Changes in students' moral development during medical school: a cohort study. Can Med Assoc J 2003;168(7):840-4. 
13. Hariharan S, Jonnalagadda S, Walrond E, Moseley H. Knowledge,attitudes and practice of healthcare ethics and law among doctors and nurses in Barbados. BMC Med Ethics 2006;9(6).

14. Medical Council of India. Salient features of regulations on graduate medical education, Gazette of India. 1997 May 17; part III, section 4.

15. Vira J. An undergraduate student's view of the medical humanities. Indian J Med Ethics 2012;9(3):161.

16. http://www.buzz4health.com/blog/2015/06/14/ethical-education-faced-by-medicalstudents/

17. http://www.afmc.ca/pages/professionalism/1CruessSlides.ppt Accessed July 2007.-

18. Medical Council of India. Salient features of regulations on graduate medical education, Gazette of India Vision 2015.

19. Balakrishnan D, Thangaraju P Vertically Integrating Model for Teaching Bioethics to the Medical Undergraduates A pragmatic approach for integration of Bioethics Teaching into the existing regular medical curriculum http://muhs.ac.in/upload/UNESCO_Bioethics_Chair_190315.pdf

Source of Funding - Nil

Conflict of Interest - Nil 